\title{
Pelatihan Penggunaan Alat KIT IPA SMP bagi Guru-Guru IPA SMP se-Kecamatan Kalasan Kabupaten Sleman untuk Mendukung Kegiatan Belajar Mengajar (KBM) dalam Mengimplementasikan Kurikulum 2013
}

\section{Training on the Use of SMP KIT Tool for Junior High School Teachers Kalasan District of Sleman Regency to Support Teaching and Learning Activities (KBM) in Implementing Curriculum 2013}

\author{
Rita Prasetyowati*, Laila Katriani, Rida Siti NM, Ariswan \\ Jurusan Pendidikan Fisika, Universitas Negeri Yogyakarta, Jl. Colombo No. 1, Yogyakarta \\ *E-mail: rita_p@uny.ac.id
}

\begin{abstract}
Abstrak
Kegiatan PPM ini bertujuan untuk mengupayakan agar para guru IPA dapat memaksimalkan pemanfaatan KIT IPA dalam pembelajaran IPA. Selain itu, kegiatan PPM ini juga dapat memberikan bekal bagi para guru IPA tentang langkah-langkah konkret pemanfaatan KIT IPA dalam pembelajaran IPA. Pemecahan masalah tersebut dapat dilakukan dengan pelatihan yang meliputi beberapa langkah kegiatan. Langkah pertama melakukan identifikasi jenis-jenis peralatan KIT IPA yang dimiliki di SMP. Langkah kedua menganalisis ketersediaan peralatan KIT IPA SMP yang sesuai dengan Kurikulum 2013 yang digunakan. Langkah ketiga melakukan pelatihan penggunaan peralatan KIT IPA SMP. Kesimpulan yang dapat diambil dari kegiatan PPM tersebut adalah para guru IPA SMP dapat memaksimalkan pemanfaatn KIT IPA guna mengimplementasikan kurikulum 2013 dalam pembelajaran IPA SMP. Selain itu para guru IPA SMP memperoleh bekal tentang langkah-langkah konkret pemanfaatan KIT IPA dalam pembelajaran IPA.
\end{abstract}

Kata kunci: kurikulum 2013, implementasi, kegiatan belajar mengajar (KBM)

\begin{abstract}
This PPM activity aims to strive for IPA teachers to maximize the utilization of IPA KIT in science learning. In addition, this PPM activity can also provide stock for science teachers about concrete steps of IPA KIT utilization in science learning. Such problem solving can be done with training that includes several steps of activities. The first step to identify the types of KIT equipment IPA owned in SMP. The second step analyzes the availability of KIT IPA SMP equipment in accordance with the Curriculum 2013 used. The third step is to train the use of KIT IPA SMP equipment. The conclusions that can be drawn from these PPM activities are the teachers of IPA SMP can maximize the utilization of IPA KIT to implement the 2013 curriculum in science lesson of SMP. In addition, SMP science teachers get supplies about concrete steps to utilize KIT IPA in science learning.
\end{abstract}

Keywords: curriculum 2013, implementation, teaching and learning activities (KBM)

\section{PENDAHULUAN}

Kurikulum 2013 sudah ditetapkan untuk diberlakukan di sekolah, dari jenjang pendidikan dasar sampai jenjang pendidikan tinggi. Pengembangan kurikulum 2013 menekankan pada penyempurnaan pola pikir, penguatan tata kelola kurikulum, pendalaman dan perluasan materi, penguatan proses pembelajaran, dan penyesuaian bebab belajar agar dapat menjamin kesesuaian antara apa yang diinginkan dengan apa yang dihasilkan.Pengembangan kurikulum menjadi hal yang sangat penting terkait dengan implemantasi kurikulum di 
lapangan. Kurikulum 2013 diharapkan mampu menjawab tantangan kemajuan jaman yang semakin global.

Implementasi kurikulum 2013 memerlukan persiapan dari berbagai komponen, salah satunya adalah persiapan tenaga guru dan tenaga kependidikan lainnya sebagai pelaksana kurikulum di lapangan. Salah satu bagian penting dari kesiapan para guru, terutama guru IPA adalah kemampuan menggunakan alat KIT dalam pembelajaran IPA. KIT pembelajaran IPA sangat mendukung dalam pembelajaran IPA. Oleh karena itu, pemerintah memberikan KIT IPA kepada SMP-SMP untuk digunakan sebagai alat pendukung dalam pembelajaran. KIT IPA tersebut sudah disertai dengan Buku Panduan atau manual apparatus yang menjelaskan komponen-komponen di dalam KIT tersebut dan beberapa percobaan yang bisa dilakukan dengan KIT tersebut.

Praktek pelaksanaan penggunaan KIT oleh para guru IPA di sekolah ternyata tidak semudah yang dibayangkan. Para guru IPA masih mengalami kesulitan dalam merancang dan menggunakan KIT tersebut dalam pembelajaran IPA, terutama karena mereka harus menyesuaikan topik percobaan sesuai dengan yang tercantum di dalam Kurikulum 2013. Masalah lain yang dihadapi adalah tidak ada laboran yang membantu para guru dalam merancang dan menyiapkan KIT untuk percobaan. Hal ini karena sebagian besar SMP tidak memiliki laboran. Sehingga para guru sangat memerlukan ketrampilan dalam men-set dan menggunakan alat KIT dengan baik.

Mencermati hal tersebut, perlu dilakukan pelatihan penggunaan alat KIT IPA SMP bagi guru-guru IPA SMP untuk mendukung Kegiatan Belajar Mengajar (KBM) dalam mengimplementasikan Kurikulum 2013.

Keterampilan proses sains dalam pembelajaran hendaknya ditingkatkan oleh para guru dengan menggunakan media pembelajaran yang sesuai, seperti KIT IPA. Pemanfaatan Media KIT IPA dalam pembelajaran IPA sangat penting, terkait
IPA adalah salah satu mata pelajaran dalam rumpun sains. Hakikat sains adalah ilmu pengetahuan yang objek pengamatannya adalah alam dengan segala isinya termasuk bumi, tumbuhan, hewan, serta manusia. Sains adalah ilmu pengetahuan yang diperoleh dengan menggunakan metodemetode berdasarkan pengamatan. Sains berkaitan dengan cara mencari tahu tentang alam secara sistematis, sehingga sains bukan hanya penguasaan kumpulan pengetahuan yang berupa fakta-fakta, konsep-konsep, atau prinsip-prinsip saja tetapi juga merupakan suatu proses penemuan. Penggunaan Media KIT IPA dalam pembelajaran IPA akan mengajak peserta didik untuk belajar IPA secara utuh, bukan sekedar menghafal konsep-konsep pengetahuan alam, namun juga mempelajari apa, mengapa, dan bagaimana konsepkonsep tersebut ditemukan melalui kegiatan percobaan.

\section{SOLUSI/TEKNOLOGI}

\section{A. Kerangka Pemecahan Masalah}

Pemecahan masalah di lapangan diatasi dengan berbagai langkah kegiatan, yaitu:

a. Langkah pertama melakukan identifikasi jenis-jenis peralatan KIT IPA yang dimiliki di SMP.

b. Langkah kedua menganalisis ketersediaan peralatan KIT IPA SMP yang sesuai dengan Kurikulum 2013 yang digunakan.

c. Langkah ketiga melakukan pelatihan penggunaan peralatan KIT IPA SMP.

\section{B. Kalayak Sasaran}

Kalayak sasaran dalam kegiatan ini meliputi para guru sains SMP seKecamatan Kalasan, Kabupaten Sleman sejumlah kurang lebih 10 guru.

\section{Metode Kegiatan}

Metode yang digunakan dalam kegiatan ini ada tiga, yaitu:

a. metode identifikasi jenis-jenis peralatan KIT IPA SMP; 
b. metode kolaborasi untuk menganalisis ketersediaan peralatan KIT IPA SMP yang sesuai dengan Kurikulum 2013 yang digunakan.

c. metode praktik pelatihan penggunaan peralatan KIT IPA SMP disertai pembuatan video penggunaan KIT IPA SMP.

\section{Rancangan Evaluasi}

Beberapa rancangan evaluasi yang diterapkan dalam kegiatan antara lain:

a. Validasi sejawat guna mengevaluasi kesesuaian peralatan KIT IPA SMP dengan Kurikulum 2013 yang digunakan.

b. Evaluasi sejawat tentang keberfungsian peralatan KIT IPA SMP dalam pembelajaran di kelas.

c. Angket untuk meminta tanggapan kalayak sasaran (guru dan siswa) tentang kebermanfaatan kegiatan ini.

\section{HASIL DAN DISKUSI}

\section{A. Waktu dan Tempat Kegiatan}

Kegiatan PPM tersebut dilaksanakan pada tanggal 18 dan 25 Agustus 2017.

Tempat kegiatan di SMP Negeri 3 Kalasan, Sleman.

\section{B. Hasil Pelaksanaan Kegiatan}

Kegiatan tersebut dilaksanakan oleh tiga orang anggota tim pelaksana PPM, yaitu Rita.P, M.Si, Laila K, M.Si dan Dr. Rida Siti NM. Kegiatan PPM dilaksanakan pada:

1). Hari Jum'at, tanggal 18 Agustus 2017 di SMP Negeri 3 Kalasan, Sleman.

Pada pertemuan itu tim PPM bersama guru-guru IPA SMP melakukan identifikasi jenis-jenis peralatan KIT IPA yang dimiliki di SMP dan menganalisis ketersediaan peralatan KIT IPA SMP yang sesuai dengan Kurikulum 2013 yang digunakan

2). Hari Jum'at, tanggal 25 Agustus $2017 \mathrm{di}$ SMP Negeri 3 Kalasan, Sleman.

Pada pertemuan itu diadakan pelatihan penggunaan peralatan KIT IPA
SMP. Selain itu juga dilaksanakan validasi sejawat guna mengevaluasi kesesuaian peralatan KIT IPA SMP dengan Kurikulum 2013 yang digunakan, serta evaluasi sejawat tentang keberfungsian peralatan KIT IPA SMP dalam pembelajaran di kelas.

Pada pelaksanaan kegiatan Hari Jum'at tanggal 25 Agustus 2017, masingmasing anggota tim pelaksana PPM memaparkan materi pelatihan sebagai berikut :

1. Penggunaan KIT IPA SMP materi Optik, disampaikan oleh Rita Prasetyowati, M.Si

Pada materi tersebut diberikan contohcontoh penggunaan KIT Optik untuk melakukan percobaan-percobaan sesuai dengan kurikulum 2013 yang digunakan.

2. Penggunaan KIT IPA SMP materi Listrik Magnet, disampaikan oleh Laila Katriani, M.Si.

Pada materi tersebut dipaparkan contohcontoh percobaan yang sesuai dengan kurikulum 2013 yang digunakan.

3. Penggunaan KIT IPA SMP materi Mekanika, disampaikan oleh Dr. Rida SN Mahmudah.

Pada materi tersebut dipaparkan contohcontoh percobaan yang sesuai dengan kurikulum 2013 yang digunakan.

Setelah memperoleh pemaparan materi dari para dosen tim pelaksana PPM, guru-guru mencoba menggunakan sendiri KIT IPA SMP untuk melakukan percobaanpercobaan yang bersesuaian dengan materi IPA (fisika) yang tertuang di dalam kurikulum 2013 yang digunakan. Kemudian jika masih ada kesulitan, guru-guru bisa berdiskusi dengan tim PPM.

Selama kegiatan PPM berlangsung, dapat diamati bahwa :

a. Sebagian guru pada awalnya masih kesulitan dalam menyusun langkahlangkah konkret untuk menggunakan KIT IPA SMP dalam pembelajaran guna mengimplementasikan kurikulum 2013.

b. Sebagian guru belum memiliki ketrampilan yang memadai dalam 
menyusun/merangkai KIT IPA SMP yang digunakan dalam pembelajaran.

Langkah-langkah yang dilakukan dalam kegiatan PPM untuk mengatasi keadaan di atas adalah :

a. Dosen pelaksana PPM memandu diskusi dengan para guru untuk melakukan identifikasi jenis-jenis peralatan KIT IPA yang dimiliki di SMP dan menganalisis ketersediaan peralatan KIT IPA SMP yang sesuai dengan Kurikulum 2013 yang digunakan

b. Dosen pelaksana PPM membantu para guru melakukan identifikasi jenis-jenis peralatan KIT IPA yang dimiliki di SMP dan menganalisis ketersediaan peralatan KIT IPA SMP yang sesuai dengan Kurikulum 2013 yang digunakan

c. Dosen pelaksana PPM membantu para guru melakukan praktek menggunakan peralatan KIT IPA dalam pembelajaran guna mengimplementasikan Kurikulum 2013.

\section{KESIMPULAN}

Kesimpulan yang dapat diambil dari kegiatan PPM tersebut adalah :

a. Para guru IPA SMP dapat memaksimalkan pemanfaatn KIT IPA guna mengimplementasikan kurikulum 2013 dalam pembelajaran IPA SMP

b. Para guru IPA SMP memperoleh bekal tentang langkah-langkah konkret pemanfaatan KIT IPA dalam pembelajaran IPA.

\section{UCAPAN TERIMA KASIH}

Pelaksana PPM mengucapkan terimakasih kepada FMIPA UNY yang telah membiayai penelitian ini melalui anggaran DIPA BLU Universitas Negeri Yogyakarta Tahun 2017.

\section{PUSTAKA}

Anna Poedjiadi. (2005). Pendidikan Sains dan Pembangunan Moral Bangsa. Bandung : yayasan Cendrawasih

Hewitt, Paul G \& etc. (2007).Conceptual Integrated Science. Pearson Education: USA

Insih wilujeng.(2010). Kompetensi IPA Terintegrasi melalui Pendekatan Keterampilan Proses Mahasiswa Pendidikan IPA. Jurnal Ilmiah Pendidikan. Nomor. ISSN: 02161370.

Purwanti Widhy Hastuti. (2013). Langkah Pengembangan Pembelajaran IPA pada Implementasi Kurikulum 2013. Disampaikan dalam Pelatihan Diklat penyusunan worksheets integrated science process skils bagi guru IPA SMP kabupaten Sleman menyongong implementasi kurikulum 201324 dan 31 Agustus 2013 